\title{
Molecular Classification of the Earthworm Aporrectodea trapezoids and the Effect of Sodium Nitroprusside and Norepinephrine on the Contractility of Crop and Gizzard Smooth Muscle
}

\author{
(From Master Thesis)
}

\author{
Nazik M.S. Othman'1, Omar A.M. Al-Habib²
}

${ }^{1}$ Dept. of Biology, Faculty of Science, University of Zakho, Zakho, Kurdistan Region, Iraq

${ }^{2}$ College of Science, Nawroz University, Duhok, Kurdistan Region, Iraq

\begin{abstract}
Background: Earthworms are considered as one of the ecologically important invertebrates with highly cryptic genetic diversity. Since the morphological methods of classification are unprecise, it is necessary to classify the species depending on molecular bases using PCR techniques. In addition, studying the effect of some agonists such as Sodium nitroprusside (SNP) and Norepinephrine (NE) on the smooth muscle of earthworm is yet poorly studied.
\end{abstract}

Objective: This study focused on the molecular classification using the mitochondrial COX 1 gene as a DNA marker. In addition, it also included the effect of nitric oxide (NO) donor sodium nitroprusside (SNP) and norepinephrine (NE) on the contractility of crop and gizzard smooth muscle of the earthworm.

Martial and Methods: For molecular classification of earthworm, DNA was extracted from crop and gizzard amplified using a universal primer (forward primer LCO14900 and specific reverse primer (SPE-CO1-A25) for amplification of the mitochondrial cytochrome oxidase subunit I (COX1) gene using touchdown PCR technique. For physiological studies, the contractility of crop and gizzard smooth muscles of earthworm was studied using an organ tissue bath containing ringer solution and recording the contraction isometrically. Also, the effect of different doses of SNP and NE on the contractility of the crop and gizzard was studied.

Results: The outcomes demonstrated that universal primers used for the amplification of 523 bps fragment by using Touch down Polymerase Chain Reaction (TD-PCR) identified the species of the earthworm as Aporrectodea trapezoids. The physiological results showed that different doses of norepinephrine $\left(1^{\star} 10-8\right.$ to $\left.1 * 10-3 \mathrm{M}\right)$ significantly reduced the contraction of crop and gizzard smooth muscles of the earthworm. While treatment with different doses of SNP (1*10-6 to 1*10-3 M) showed a non-significant $(P>0.05)$ relaxing effect.

Conclusion: The obtained sequence identified the species of earthworm as Aporrectodea trapezoids, it is registered and deposited in the GenBank under accession number (MW354675). Phylogenic analysis of Aporrectodea trapezoids using cox1 indicated its relationship to other strains from the USA. Physiologically, Norepinephrine exerts an inhibitory effect on the Smooth Muscle cell contractility, whereas, SNP produced no effect on the amplitude of the contractility of the crop and gizzard SMCs.

KEYWORDS: Molecular Classification, Earthworm, Aporrectodea trapezoids. SNP, NE, Crop-Gizzard, Smooth Muscle Cells

\section{Introduction}

Earthworms are considered as the most important invertebrates for their beneficial role as soil biomanipulator and decomposer (Aira et al., 2007). Their effect is represented by infiltration of water into the soil, enhanced organic compounds, cytokines, and auxin in the ground (Krishnamoorthy and Vajranabhaiah, 1986; Katsvairo et al., 2007). Approximately about 3000 species of earthworms are described, which inhabit terrestrial, freshwater, and marine ecosystems (Qiu, 1999). Adult earthworm species can be identified by dissection of the male genitalia (Tsai et al. 2000; Shen et al. 2003); however, this method needs an intensive labor, time-consuming, and very difficult for non-specialists especially when dealing with several different earthworm species. In addition, identification is limited to adult stages of the 
worms. Thus, the use of DNA barcodes, (short sequences from standardized regions of the genome) has been regarded as a promising approach to resolve the taxonomic dilemma. The sequence diversity in mitochondrial cytochrome-c oxidase I (COXI) gene has been evaluated as a tool for resolving differences among different earthworm species and provides a useful complement to traditional morphological taxonomy (Huang et al., 2007). The cytochrome-c oxidase I (COX1) gene is present in vertebrate and invertebrate animals which rarely show insertions and deletions. Thus, the COX1 gene, is considered as the DNA barcode for taxonomic and molecular identification of earthworm species (Hebert et al., 2003).

Earthworms smooth muscle consists of myosin and the filament systems are arranged as circular and longitudinal muscles (Sulbarán et al., 2015). The activity of the smooth muscle is regulated by the Cropgizzard of the earthworm which are responsible for gut motility and the efficiency of the digestive system (Krauss, 2007). Sodium nitroprusside (SNP) and Norepinephrine (NE) regulate the activity of the gut (Krajniak and Khlor, 1999).

Sodium nitroprusside (SNP) also acts as a donor for nitric oxide (NO) which activates guanylate cyclase in vascular smooth muscle and increases cellular production of cyclic guanosine monophosphate (cGMP) (Grizelj et al., 2014). Hence, Nitric oxide has different physiological roles such as proliferation, migration, cell differentiation and regulation of blood pressure (Tonelli et al., 2013). It has shown that inhibition of vascular smooth muscle cell (VSMC) proliferation produced by SNP is induced by epidermal growth factor receptor (Yu et al., 1997). Norepinephrine is considered as one of the primary catecholamines, affecting the behavior and physiology of both vertebrates and invertebrates and it is considered as a central, and peripheral transmitter in the visceral motor system secreted due to acute stress
(Frederick and Eichinger, 2004).

Thus, the present study focused on the classification of the earthworm based on the molecular techniques which represent the first record in the area. In addition, it is also focused on the effect of $\mathrm{NO}$ and Norepinephrine on the contractility of crop and gizzard smooth muscle cells.

\section{Material and methods}

\subsection{Study Aera}

About 50 earthworms were collected from Bezeh-Betaz (Zakho city, Duhok governorate, Kurdistan RegionIraq). The animals were collected from the soil using hand sorting methods. The collected earthworms were transported to the laboratory for acclimatization to laboratory conditions. The study was carried out at the Advanced Physiology Research Lab of Biology Department, Faculty of Science, University of Zakho during the period between August $1^{\text {st }} 2018$ to December $2^{\text {th }} 2019$.

\subsection{Sample collection and preparation:}

Earthworms were rinsed with tap water to remove any excess soil, then anesthetized by using ethanol (5\%) for 10 minutes until the earthworm stop moving. The earthworms were dissected dorsally and their cropgizzards were isolated.

\subsection{DNA extraction and Amplification by using COX}

\section{1 gene}

Twenty mg of crop-gizzard tissue was collected, and DNA was extracted using AddPrep Genomic DNA Extraction Kit supplied with spin column (AddBio, Korea) as per manufacturer guideline of the kit. Universal forward primer LCO14900 and specific reverse primer SPE-CO1-A25 were used to amplify a part of the mitochondrial cytochrome oxidase subunit I (COX1) gene. The volume of each PCR reaction was carried out in $35 \mu \mathrm{l}$ reaction cocktail, containing $\left(\mathrm{dNTP}, \quad\left(\mathrm{NH}_{4}\right)_{2} \mathrm{SO}_{4}, \mathrm{MgCl}_{2}\right.$, hot start Taq DNA polymerase (BioTherm, GeneCraft) and $4 \mu \mathrm{l}$ of DNA extract. Double distilled water instead of DNA was 
included as a negative control to check for contamination.

Touchdown PCR was used for amplification of DNA samples. The setting for polymerase chain reaction was as follows: One cycle (initial denaturation) for 2 minutes at $94^{\circ} \mathrm{C}$, followed by five cycles of 15 seconds of denaturation stage at $94^{\circ} \mathrm{C}, 15$ seconds of annealing at $51{ }^{\circ} \mathrm{C}$, and 45 second of extension at $72{ }^{\circ} \mathrm{C}$, followed by 35 of cycles of 15 seconds of denaturation at $94^{\circ} \mathrm{C}$, 30 seconds of annealing at $54{ }^{\circ} \mathrm{C}$, and 45 seconds of extension at $72^{\circ} \mathrm{C}$, then 2 minutes at $72^{\circ} \mathrm{C}$ (final extension)

\subsection{DNA Sequencing}

The amplified DNA by using PCR was send to Macrogene Company (South Koera) for DNA sequencing. Both primers (forwards and reverse) were used for DNA sequence by using automated DNA sequence analyzer (3730 XL DNA genetic analyzer). BioEdite and editor (7.2) was used to check and align the sequences and to calculate the similarity among them. The phylogenic tree was conducted by using MEGA-X (10.2).

\subsection{Physiological Studies}

The physiological studies were performed on anesthetized earthworm by the removal of exposed crop and gizzard, rinsed with earthworm physiological solution and connected to the tissue holder by using stainless steel wires with hooks and immersed in the tissue bath glass chamber. The other end of the tissue was connected to a force transducer. The force transducer was connected to transbridge amplifier of ADI PowerLab Data Acquisition System and Computer Running Chart Software (Version 7). The rate and amplitude of contraction and relaxation were recorded by the tension developed at recording system. The relaxation rate was defined as $\mathrm{T}$ relaxation/ $\mathrm{T}$ contraction expressed as a percentage. The isolated crop and gizzard were pretreated with Ringer solutions for 20 minutes, then exposed to different doses of SNP $\left(1 \times 10^{-6}\right.$ to $\left.1 \times 10^{-3} \mathrm{M}\right)$ and NE $\left(1 \times 10^{-8}\right.$ to $\left.1 \times 10^{-3} \mathrm{M}\right)$ for 3 minutes per each dose of the desired agonist and the half-maximal inhibitory concentrations (IC50s) were established for both crop and gizzard separately.

\subsection{Statistical Analysis}

The data collected from all conducted experiments were subjected to statistical analysis using a two-way analysis of variance (ANOVA) supported by Bonferroni test when carrying out a pairwise comparison between the same dose of different groups using GraphPad prism program (Version 8). Analysis of variance for repeated measurements was applied to data consisting of repeated observations at successive time points. P-values less than $0.05(\mathrm{P}<0.05)$ were considered statistically significant. In figures, the symbols $\left({ }^{*}, * *\right.$ and $\left.{ }^{* * *}\right)$ representing that the mean differences are significant at 0.05, 0.01, and 0.001 levels, respectively.

\section{Results and Discussions}

\subsection{Molecular Classification}

The earthworm species used in this study was classified on molecular basis using the amplification of COX1 gene. The DNA concentrations ranged from (10.1 to $230 \mathrm{ng} / \mathrm{ul}$ ) and its purity at wavelengths 260/280 was between 1.8 to 2.0 using Nanodrop 2000 spectrophotometer. The size of the band obtained from the amplification of COX1 gene DNA of the isolated crop and gizzard tissues of the earthworm was 523 bps (Fig. 1). Out of 45 PCR products, five were sent to Macrogene Company (South Korea) for DNA sequencing. The sequencing results were submitted to BioEdite program for sequence alignment. The obtained sequence was confirmed that the species is Aporrectodea trapezoids. The obtained sequence was deposited in GeneBank under the accession number (MW354675). 


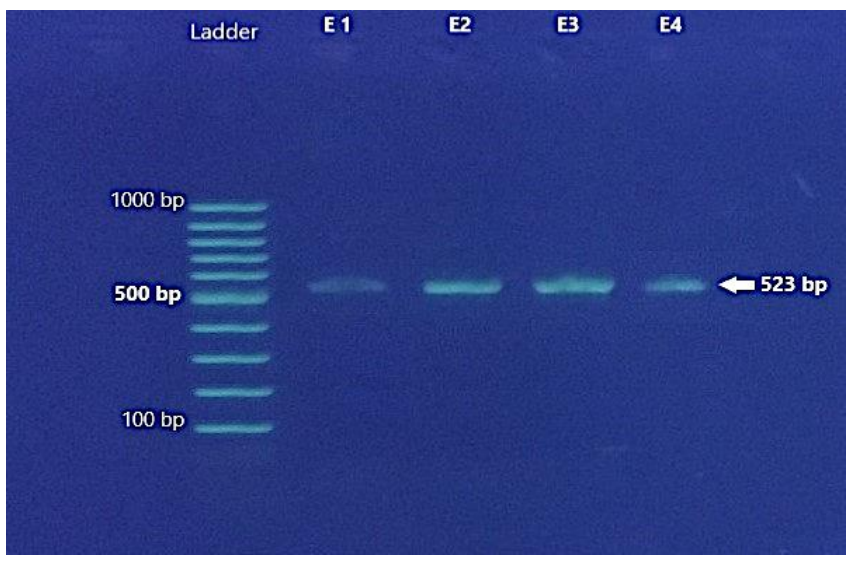

Figure (1): Agarose gel electrophoresis (1.5\%) of COX1 gene

PCR product. DNA ladder, Lanes from E1-E4 amplicon size 523 bps.

BLASTE similarity analysis showed that the obtained sequence has 98 - 100\% similarity with the following annotated sequences in GenBank: MK971712 from USA, MG 421216 from CANAD, KT 073953 from Australia, KF205975 from China, MT968742 from Iran, and JN 850551 from Portugal (Fig. 2)

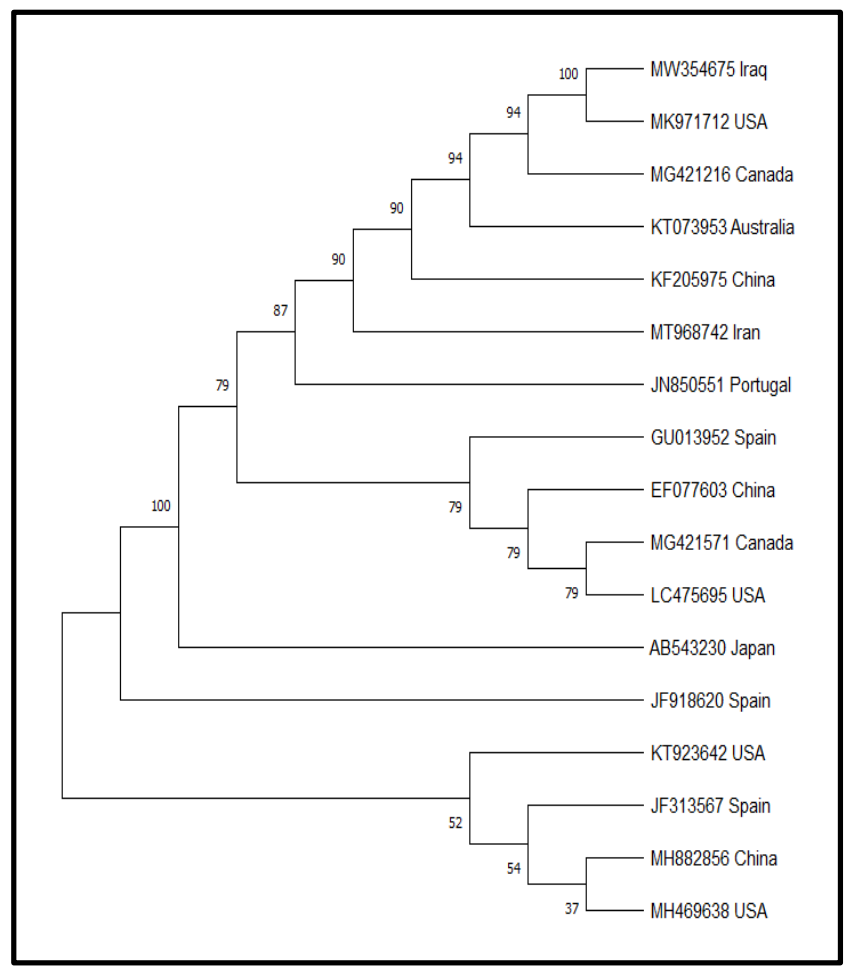

Figure (2): Molecular phylogenetic analysis using alignment by codon Muscle using P-distance as nucleotide substitution models for Aporrectodea trapezoids isolated from soil. Neighbor-Joining method was used for inferred the evolutionary history. The percentage of replicate trees in which the associated taxa clustered together in the bootstrap test (1000 replicates) is shown next to the branches. Evolutionary analyses were conducted in MEGAX VERSION 10. Accession numbers of Aporrectodea trapezoids isolated in this study (MW354675) compared with reference strains.

The phylogenic tree was constructed by comparing the obtained sequence with other references obtained in GenBank (Figure 2). The phylogenic tree confirmed that the obtained results belong to Aporrectodea trapezoids. The tree of $A$. trapezoids showed high relatedness among isolates of the same species. All compared sequences were generally assigned into two main clusters; the present study sequenced sample belonged to the first cluster, and MW354675 (Iraq) and MK971712 (USA) are sister taxa in $100 \%$ of the bootstrap resampling. The other well-supported group includes reference sequences that shared the same common ancestor with different bootstrapping resampling.

It is difficult to precisely classify the earthworm species depending on the depth of location, the size, and color of the earthworm, since some features may change depending on the maturity of the earthworm. Therefore, the molecular tool was used for the identification of the genus as well as the species of the earthworms (Gabriella et al., 2019). The combined use of the morphological and molecular techniques allowed accurate classification of several species in different localities (Pop et al., 2003; Chang et al., 2009 and Decaens, et al, 2013). Furthermore, they indicated that the opportunities of identification of the earthworm species by DNA barcoding is more accurate and accessible. It is worthwhile to mention that this is the first molecular study in Duhok governorate for the classification of earthworm species using COX1 gen barcoding and for establishing a phylogenetic relationship between earthworm species worldwide.

\subsection{The Physiological Studies}

Figure (3A) illustrate the effect of Norepinephrine on the amplitude contraction peaks of earthworm crop smooth muscle treated with different NE 
concentrations $\left(1^{*} 10^{-8}\right.$ to $\left.1^{*} 10^{-3} \mathrm{M}\right)$. It can be noticed that the amplitude contraction of the crop after treatment with norepinephrine had reduced comparing with that of the control (Fig 3-A).

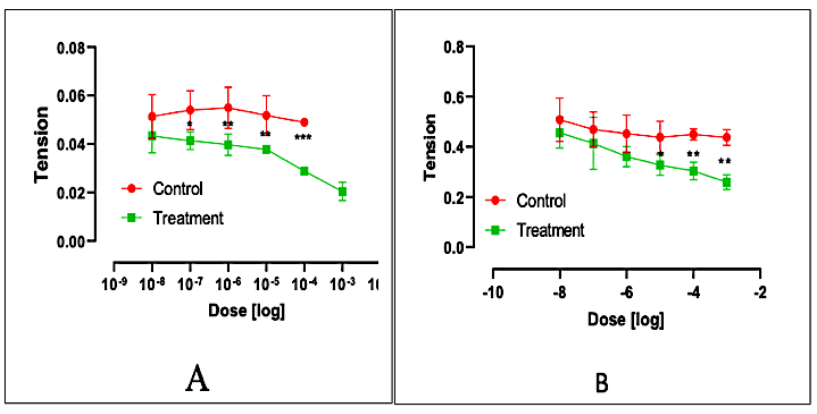

Figure (3): Cumulative dose-response curves for the relaxant effects of NE on contraction. amplitude of (A) Crop, (B) Gizzard.

This might be due to the relaxant effect of NE which in turn reduced the tension of the smooth muscle cells contraction as an inhibitory agent. The differences between both curves (control and treatment) were significant $(\mathrm{P}<0.05)$ at most applied doses, except the first dose, which was non-significant $(\mathrm{P}>0.05)$ as compared to control. The interaction between time and treatment doses was highly significant $(\mathrm{P}<0.01)$, where the worms treated with epinephrine at a dose of $1^{*} 10^{-3}$ $M$ recorded the lowest relaxation effect. which mean that the last dose of epinephrine plays a vital role to exhibits a maximum inhibitory effect on the amplitude.

Figure (3B) represents the effect of NE on contraction amplitude of isolated gizzard. It can be observed that the contraction amplitude of gizzard smooth muscle cells after treatment with norepinephrine decreased the developed tension as compared to the control. This can be explained as due to the relaxant effect of SNP, which in turn inhibited the generated tension. Statistical analysis of the results revealed the presence of significant differences between both curves at the levels of $(P<0.05)$ at the fourth dose $\left(1^{*} 10^{-5} \mathrm{M}\right)$ and at $(P<0.01)$ level at the last two doses $\left(1^{*} 10^{-4} \mathrm{M}\right.$ and $1^{*} 10^{-}$ 3). It is difficult to compare these novel results of the present study since no data are available on the effect of NE and SNP on earthworm crop and gizzard smooth muscles.

The results of the effect of Sodium SNP on the crop are shown in Figure (4-A). That showed a decrease in the amplitude of contraction in SNP treated crop as compared to the control except at a dose of $3^{\star} 10^{-3}$ which enhanced the tension of contraction. However, the differences between both curves were nonsignificant $(\mathrm{P}>0.05)$ at all applied doses. This reflects the mild relaxant effect of SNP on crop's smooth muscle cells which leads to the reduction in the tension of contraction. The peak point appeared at a doe of $3^{*} 10^{-3}$ not mean superiority, but it may be due to individual variation among the replicates. ANOVA analysis, revealed the

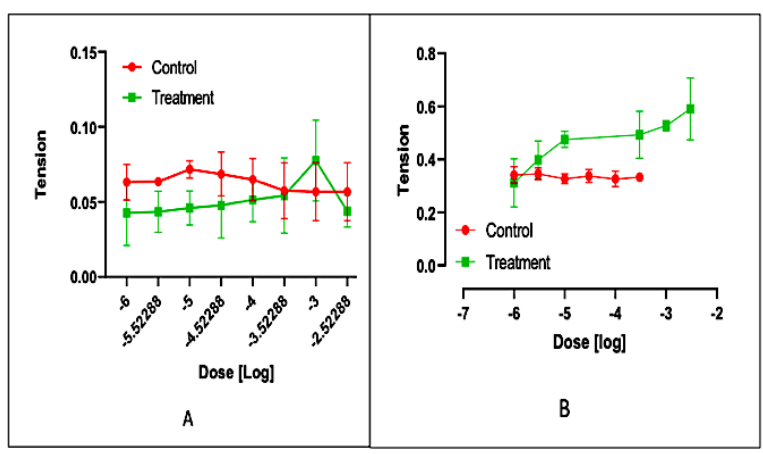

Figure (4): Cumulative dose-response curves for the relaxant effects of SNP on contraction amplitude of (A) Crop, (B) Gizzard.

presence of significant difference $(P<0.05)$ in the interaction between the applied doses, therefore resulted in higher point tension in the amplitude of the response curve at the dose $\left(1^{*} 10^{-6} \mathrm{M}\right)$ was interacted positively and significantly with the SNP treatment, but in contrast the dose $1^{*} 10^{-3} \mathrm{M}$ was interacted negatively and significantly $(\mathrm{P}<0.01)$. Figure $(4 . \mathrm{B})$ shows curves of both control and gizzard treated with different doses SNP on the contraction amplitude. In contrary to NE, SNP caused a considerable but nonsignificant $(\mathrm{P}>0.05)$ enhancement in the contraction amplitude of the gizzard smooth muscle as compared with the control. This indicate that despite the relaxant effect of SNP on the rat's aortic smooth muscle, but it 
failed to produce any relaxation in gizzard smooth muscle cells (Qadir, 2012; Khalil, 2016). This may indicate the variation between the mechanism of contraction in earthworm smooth muscle cells compared to those of the vertebrate.

It is clear from the results of the current study that norepinephrine plays a major role in the hyperpolarization and subsequent relaxation of earthworm smooth muscles cells by enhancing the activity of ionic pump (primarily $\mathrm{Na}^{+}-\mathrm{K}^{+}$pump) only in the presence of $\mathrm{Ca}^{2+}$ in the bathing medium (Volkov et al., 2011a). In a study on the effect of Norepinephrine and Epinephrine on Resting Membrane Potential in Body Wall Muscle of Earthworm Lumbricus Terrestris, Volkov et al. (2011b) found that Ouabain abolished the hyperpolarizing effect of norepinephrine and decreased resting membrane potential (RMP) of muscle cells. Due to the lack of information on the effect of SNP in earthworm, it is difficult to compare the novel results of the current study. However, it is well known that SNP usually induced relaxation in the vascular smooth muscle (VSM) of rat's which mediated through activation of the sodium-potassium pump (Na+/K+-ATPase) and/or membrane hyperpolarization (Qadir, 2012, Khalil, 2016). while the result of the current study revealed no such effect on the amplitude contractility of the crop and gizzard smooth muscle of earthworm.

\section{Conclusion}

The obtained sequence of the earthworm was identified as Aporrectodea trapezoids and deposited in the GenBank under accession number (MW354675). Phylogenic analysis of Aporrectodea trapezoids COX1 indicated a relationship to other strains from USA. Norepinephrine may play an important role in the hyperpolarization of earthworm smooth muscle by enhancing ionic pump activity (primarily $\mathrm{Na}+, \mathrm{K}+$ pump). Therefore, norepinephrine has an inhibitory effect on the smooth muscle. At the same time, SNP does not affect the amplitude contractility of the crop and gizzard smooth muscles.

\section{References}

1. Aira, M., Monroy, F., \& Domínguez, J. (2007). Microbial biomass governs enzyme activity decay during aging of worm-worked substrates through vermicomposting. Journal of Environmental Quality, 36(2), 448-452.

2. Chang, C. H., Rougerie, R., \& Chen, J. H. (2009). Identifying earthworms through DNA barcodes: Pitfalls and promise. Pedobiologia, 52(3), 171-180.

3. Frederick, J., \& Eichinger, D. (2004). Entamoeba invadens contains the components of a classical adrenergic signaling system. Molecular and biochemical parasitology, 137(2), 339-343.

4. Grizelj Ivana, Ana Čavka, Shane A. Phillips. (2014). Vascular dysfunction and exercise. Periodicum Biologorum, 116(1), 15-19.

5. Hebert, P. D., Cywinska, A., Ball, S. L., \& Dewaard, J. R. (2003). Biological identifications through DNA barcodes. Proceedings of the Royal Society of London. Series B: Biological Sciences, 270(1512), 313-321.

6. Huang, J., Xu, Q., Sun, Z. J., Tang, G. L., \& Su, Z. Y. (2007). Identifying earthworms through DNA barcodes. Pedobiologia, 51(4), 301-309.

7. Krauss, J. (2007). FMR Famide-activated signal transduction pathways in the crop-gizzard of the Earthworm Lumbricus terrestris. M. Sc. Thesis, Humboldt State University.

8. Katsvairo, T. W., Wright, D. L., Marois, J. J., Hartzog, D. L., Balkcom, K. B., Wiatrak, P. P., \& Rich, J. R. (2007). Cotton roots, earthworms, and infiltration characteristics in sod-peanut-cotton cropping systems. Agronomy Journal, 99(2), 390-398.

9. Khalil, S. S. (2016). The Relaxant Effect of NO, CO and their Time Dependent Interactions on Rat's Aortic Rings with a Special Emphasis on the Role of $\mathrm{Ca} 2+$ and $\mathrm{K}+$ Channels. Thesis Submitted to the Council of the Faculty of Science at University of Zakho.

10. Krajniak, K. G., \& Klohr, R. W. (1999). The effects of FMRFamide, serotonin, and acetylcholine on the isolated crop-gizzard of the earthworm, Lumbricus terrestris. Comparative Biochemistry and Physiology Part A: Molecular \& Integrative Physiology, 123(4), 409415.

11. Krishnamoorthy, R. V., \& Vajranabhaiah, S. N. (1986). Biological activity of earthworm casts: an assessment of plant growth promotor levels in the casts. Proceedings: Animal Sciences, 95(3), 341-351.

12. Motulsky, H. (2015). Essential biostatistics: a nonmathematical approach. Oxford University Press.

13. Pop, A.A., Wink, M., Pop, V.V. (2003). Use of 18S, $16 S$ rDNA and cytochrome $\mathrm{c}$ oxidase sequences in earthworm taxonomy (Oligochaeta, Lumbricidae). Pedobiologia 47, 428-433.

14. Qadir, A.B., (2012). Modulation of aortic potassium channels activity by gasotransmitters signaling. Ph.D. 
thesis. Zakho University. Kurdistan region-Iraq

15. Qiu, J.P., 1999. Earthworms and their application in environment protection. I. Earthworms and their functions in ecosystem. J. Shanghai Agri. Coll. 17,227232.

16. Shen, H.P., Tsai, C.F., Tsai, S.C., 2003. Six new earthworms of the genus Amynthas (Oligochaeta: Megascolecidae) from central Taiwan. Zool. Stud. 42, 479-490

17. Sulbarán, G., Alamo, L., Pinto, A., Márquez, G., Méndez, F., Padrón, R., \& Craig, R. (2015). An invertebrate smooth muscle with striated muscle myosin filaments. Proceedings of the National Academy of Sciences, 112(42), E5660-E5668.

18. Tonelli, A. R., Haserodt, S., Aytekin, M., \& Dweik, R. A. (2013). Nitric oxide deficiency in pulmonary hypertension: Pathobiology and implications for therapy. Pulmonary circulation, 3(1), 20-30.

19. Tsai, C.F., Tsai, S.C., Liaw, G.J., 2000. Two new species of protandric pheretimoid earthworms belonging to the genus Metaphire (Megascolecidae: Oligochaeta) from Taiwan. J. Nat. Hist. 34, 1731-1741.

20. Volkov, E. M., Nurullin, L. F., Nikol'skii, E. E., \& Blokhina, G. I. (2001). Effects of Norepinephrine and Epinephrine on Resting Membrane Potential in Body Wall Muscle Cells of Lumbricus Terrestris Eearthworm.Bulletin of experimental biology and medicine, 132(3), 821-823.

21. Volkov, M. E., Petrov, A. M., Volkov, E. M., \& Zefirov, A. L. (2011). Study of the vesicular cycle in nerve structures in somatic muscle of earthworm (Lumbricus terrestris). Cell and Tissue Biology, 5(6), 612-618.

22. Yu, X., Bates, J. B., Jellison Jr, G. E., \& Hart, F. X. (1997). A stable thin-film lithium electrolyte: lithium phosphorus oxynitride. Journal of the electrochemical society, 144(2), 524. 